\title{
Tankyrase: Function and Tankyrase Inhibitor in Cancer
}

\author{
Mi Kyung Kim $^{\dagger}$,* \\ Department of Systems Biology, Yonsei University, Seoul 03722, Korea
}

\begin{abstract}
Tankyrases are multifunctional poly (ADP-ribose) polymerases that regulate a variety of cellular processes including WNT signaling, telomere maintenance, regulation of mitosis, and many others. Tankyrases interact with target proteins and regulate their interactions and stability through poly (ADP-ribosyl) ation. In addition to their roles in telomere maintenance and regulation of mitosis, tankyrase proteins regulate tumor suppressors such as AXIN, PTEN, and AMOT. Therefore, tankyrases can be effective targets for cancer treatment. Tankyrase inhibitors could affect a variety of pathways that are carcinogenic (essential for the unlimited proliferation of human cancer cells), including WNT, AKT, YAP, telomere maintenance, and regulation of mitosis. Recently, new aspects of the function and mechanism of tankyrases have been reported and several tankyrase inhibitors have been identified. Also, it has been proposed that the combination of conventional chemotherapy agents with tankyrase inhibitors may have synergistic anti-cancer effects. Based on this, it is expected that more advanced and improved tankyrase inhibitors will be developed, enabling new therapeutic strategies against cancer and other tankyrase linked diseases. This review discusses tankyrase function and the role of tankyrase inhibitors in the treatment of cancer.
\end{abstract}

Key Words: Tankyrase, WNT signaling, Tankyrase inhibitor, XAV939

\section{서 론}

폴리(ADP-리보스) 폴리머라아제(PARP)는 다양한 세포 및 분자 과정에 관여하는 거대단백질 계열이다. 이 효 소는 번역 후 변형, 즉 표적단백질을 폴리-ADP 리보실 화(PARsylated) (Bürkle et al., 2005; Riffell et al., 2012; Haikarainen et al., 2014)하여 DNA 손상 수리(Malanga et al., 2005), 세포 스트레스 신호 전달(Luo et al., 2012), 유전자 전사(Kraus et al., 2003; Yeh et al., 2007) 및 노화(Beneke et al., 2007)를 포함한 수많은 세포 과정을 조절한다. Tankyrase 결합단백질은 6-amino acid tankyrase-binding motif ( $\mathrm{RxxAxG}$ 또는 RxxPxG 또는 RxxxxG) (Huang et al., 2009; Guettler et al., 2011; Li et al., 2015)를 사용하여 tankyrase 단백질과 상 호 작용한다. Tankyrase 단백질은 telomere 유지 보수(Smith et al., 2000), WNT 신호(Huang et al., 2009), 유사 분열(Chang et al., 2005; Chang et al., 2005; Kim et al., 2012, 2014), 포도당 대사(Guo et al., 2012; Ha et al., 2012), 유전성 질병 체르노 빌즘(Guettler et al., 2011; Levaot et al., 2011) 등 다양한 세 포 기능에 관여한다.

최근까지의 항암제는 kinase inhibitor에 초점을 맞추어 개발되었으나 이러한 화합물들에 대한 부작용들이 보고 되면서 새로운 영역에서의 타깃을 이용한 항암제의 개발 이 요구되고 있다. WNT 신호 전달 경로(WNT signaling pathway)는 배아 발생, 조직 항상성 및 많은 질병과 연관 되어 다양한 기능을 수행하기 때문에 WNT 신호 전달 경

Received: May 28, 2018 / Revised: August 24, 2018 / Accepted: August 24, 2018

* Professor.

${ }^{\dagger}$ Corresponding author: Mi Kyung Kim. Department of Systems Biology, Yonsei University, Seoul 03722, Korea.

Tel: +82-2-2123-2709, Fax:+82-2-312-5657, e-mail: biokyung@gmail.com

(C) The Korean Society for Biomedical Laboratory Sciences. All rights reserved.

(C) This is an Open Access article distributed under the terms of the Creative Commons Attribution Non-Commercial License (http://creativecommons.org/licenses/by-nc/3.0/) which permits unrestricted non-commercial use, distribution, and reproduction in any medium, provided the original work is properly cited. 


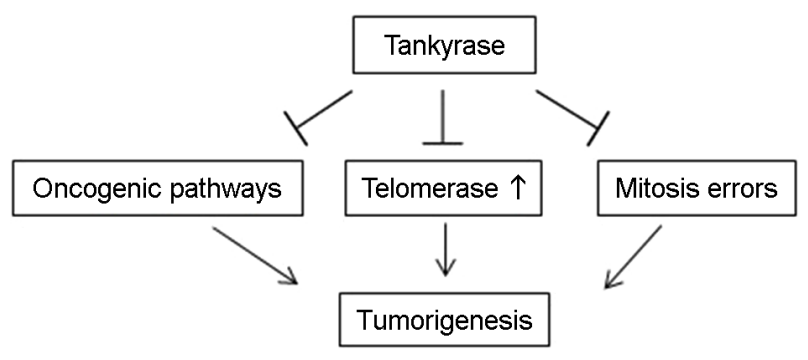

Fig. 1. Different biological tankyrase functions are relevant to cancer, including oncogenic pathways (WNT, YAP, and AKT), telomere maintenance, and regulation of mitosis.

로를 조절할 수 있는 새로운 인자의 발견 및 이의 조절을 통한 항암제의 개발이 요구되고 있다. 비정상적인 WNT 신호 전달 경로의 활성화는 $\beta$-catenin 축적을 야기시켜 다 양한 발암 유전자의 전사를 촉진하여 대장암, 폐암 등의 발병과 진행의 원인이 된다(C.G.A., 2012; Nguyen et al., 2009; Pacheco-Pinedo et al., 2011). 최근 연구에 따르면 tankyrase 조절에 의한 WNT 신호 전달 경로와의 연관성이 대장암 세포에서 입증되었고, 이에 바탕으로 관련 약물 개 발이 활발히 이루어지고 있다(Wu et al., 2016). 또한, tankyrase가 발암 유전자인 YAP와 종양 억제 인자인 PTEN 을 조절한다는 보고가 있다(Wang et al., 2015; Li et al., 2015; Wang et al., 2016).

본 논문에서는 tankyrase와 암 발생 기전과의 상관관계 및 암 치료제로서의 tankyrase inhibitor의 중요성과 유용성 을 소개하고자 한다.

\section{본 론}

\section{Tankyrase와 암}

Tankyrase 단백질은 종양 발생 경로(WNT, YAP, AKT), 텔로미어 유지, 유사 분열 등을 포함한 과정들과 연관되 어 암의 발병과 진행을 조절한다(Fig. 1).

종양 발생 경로: Tankyrase는 종양 발생 경로(WNT, YAP 및 $\mathrm{AKT}$ )와 연관되어 있는데, WNT 신호 전달 경로는 암 을 포함한 많은 생물학적 과정을 조절한다(Clevers, 2006). WNT 신호 전달 경로는 adenomatous polyposis coli (APC), AXIN, glycogen synthase kinase $3 \beta$ (GSK3 $\beta$ ) (Rubinfeld et al., 1996)를 포함한 $\beta$-catenin 분해복합체에 의한 후속반응기 $\beta$-catenin의 단백질 분해를 조절한다. GSK3 $\beta$ 와 $\mathrm{CKI}$ 에 의해
인산화된 APC 단백질은 $\beta$-catenin 분해복합체로 유도한다. $\mathrm{AXIN}$ 은 이 분해복합체가 $\beta$-catenin 인산화 및 유비퀴틴화 가 진행되도록 한다. Tankyrase에 의한 AXIN PARsylation 은 유비퀴틴-프로테아좀 경로에 의한 AXIN 분해를 유도 하고, 이어서 AXIN 분해는 $\beta$-catenin 분해복합체의 파괴를 유발한다. 방출된 $\beta$-catenin이 핵으로 이동하고 WNT 표적 유전자의 전사 조절을 활성화 한다(Huang et al., 2009). 종 양 억제 인자인 $\mathrm{APC}$ 는 대장암의 $80 \%$ 이상에서 돌연변이 가 일어나고(C.G.A., 2012), tankyrase가 WNT 신호 전달 경 로를 조절하기 때문에 tankyrase inhibitor는 대장암에 대해 매우 유용하다. 실제로, tankyrase inhibition은 APC 돌연변 이 대장암 세포에서 WNT 신호 전달 경로 및 종양 성장 을 억제하고(Huang et al., 2009; Waaler et al., 2012; Lau et al., 2013), WNT 신호 경로의 차단을 통해 대장암 세포주의 항 암제의 감수성을 증가시킨다(Clevers, 2006). 또한, tankyrase inhibitor를 통한 WNT 신호 전달 경로의 길항 작용은 폐 암 세포에 효과적이고(Nguyen et al., 2009; Pacheco-Pinedo et al., 2011), tankyrase inhibitor가 폐암 세포에서 항 종양 표적 으로 작용하는 예가 보고되었다(Casás-Selves et al., 2012; Busch et al., 2013).

YAP은 발암단백질(oncoprotein)과 히포(Hippo) 신호 전 달 경로의 핵심 작용기로 암에 관여하는 것으로 나타 났다(Dong et al., 2007; Harvey et al., 2013; Mo et al., 2014). Angiomotin 계열의 단백질(AMOT)은 YAP 억제 조절자이 다(Wang et al., 2011). 최근의 연구에 따르면 tankyrase inhibition는 tankyrase 매개 angiomotin 단백질 분해를 저해하 여 angiomotin 계열의 단백질을 안정화시킴으로써 YAP 종 양 발생을 억제한다는 것을 보여 준다(Wang et al., 2015; Wang et al., 2016). YAP 신호 전달이 RAF와 MEK 표적 암 치료법을 포함한 약물 내성에 관여함이 입증되었고(Lin et al., 2015), tankyrase inhibitor에 의한 EGFR 성장 억제 증가 가 보고되었다(Wang et al., 2016). 이러한 연구 결과는 YAP 발암 경로를 타깃으로 하는 암에 대한 tankyrase inhibitor 의 치료 가능성을 뒷받침한다.

PTEN은 중요한 종양 억제 인자이며 PTEN 돌연변이는 여러 암(Li et al., 1997; Steck et al., 1997)과 코덴증후군(Liaw et al., 1997)과 관련 있다. Tankyrase inhibition에 의한 PTEN 안정화는 AKT 인산화의 하향 조절을 유도하여 세포 증식 과 종양 성장을 억제한다(Li et al., 2015). 이러한 연구 결과 는 AKT 발암 경로를 타깃으로 하는 암에 대한 tankyrase inhibitor의 치료 가능성을 뒷받침한다. 
Table 1. Tankyrase inhibitors as therapeutic targets for cancer

\begin{tabular}{lll}
\hline \hline \multicolumn{1}{c}{ Tankyrase inhibitors } & \multicolumn{1}{c}{ Cancers } & \multicolumn{1}{c}{ References } \\
\hline JW 74 & Osteosarcoma & Stratford et al., 2014 \\
\hline \multirow{3}{*}{ XAV939 } & Neuroblastoma & Tian et al., 2014 \\
& Colorectal cancer (CRC) & Huang et al., 2009 \\
& Lung cancer & Busch et al., 2013 \\
& Breast cancer & Bao et al., 2012 \\
\hline \multirow{2}{*}{ AZ1366 } & Non-small cell lung cancer (NSCLC) & Scarborough et al., 2017 \\
& Colorectal cancer (CRC) & Quackenbush et al., 2016 \\
\hline \multirow{2}{*}{ IWR-1 } & Lung cancer & Busch et al., 2013 \\
\hline G007-LK & Osteosarcoma & Martins-Neves et al., 2018 \\
\hline JW55 & Colorectal cancer (CRC) & Lau et al., 2013 \\
\hline \multirow{2}{*}{ NVP-TNKS656 } & Colorectal cancer (CRC) & Waaler et al., 2012 \\
\hline WIKI4 & Colorectal cancer (CRC) & Arqués et al., 2016 \\
\hline Tetrazoloquinoxaline 41 & Non-small cell lung cancer (NSCLC) & Wang et al., 2016 \\
\hline
\end{tabular}

Telomere: Telomere는 염색체 말단에 위치하는 복합체 로 염색체 구조의 안정성 유지에 중요한 역할을 한다 (Blackburn et al., 1978). 세포 분열 시마다 짧아지는 telomere는 telomerase에 의하여 합성되는데 이러한 telomerase 의 활성은 대부분의 암세포들에서 발견되는 특징이다(Kim et al., 1994; Shay et al., 1997). Tankyrase은 암세포에서 telomerase 저해를 조절하여 암세포의 지속적인 증식을 방해 한다(Smith et al., 2000; Chang et al., 2003). 이러한 측면에서 볼 때 telomerase의 활성 억제는 선택적인 암 치료를 위한 새로운 방법 중의 하나로 제안되었다. Tankyrase inhibitor 와 telomerase inhibitor의 조합은 위암 및 폐암 세포주에서 상승된 항암 효과를 보였고(Zhang et al., 2010; Ozaki et al., 2012), 폐암 세포의 자멸을 촉진하고 세포 증식을 억제하 는 것으로 나타났다(Lu et al., 2013). 이러한 결과는 tankyrase inhibitor의 항암 효과 및 tankyrase inhibitor와 telomerase inhibitor의 조합에 의한 새로운 항암 치료 가능성을 뒷받 침한다.

유사 분열: 유사 분열 조절제: Tankyrase는 유사 분열 (mitosis) 시 sister telomere cohesion 분해, 중심체(centrosome) 단백질의 조절에 관여한다. Tankyrase inhibition 시 유사 분열 지연과 비정상적인 중심체 구조 및 기능 오류 등이 발생한다(Kim et al., 2012, 2014; Chang et al., 2005;
Chang et al., 2005; Ozaki et al., 2012). 비정상적인 중심체는 암에 관여하고 염색체 오류(chromosome missegregation) 및 이수 배체(aneuploidy)에 기여하여 악성 진행을 촉진한다 (Duensing et al., 2001; Boveri et al., 2008; Ganem et al., 2009; Guerrero et al., 2010). 이와 같은 결과를 바탕으로 tankyrase inhibitor가 유사 분열 조절제로 작용하여 암 치료의 잠재 적 표적으로 가능성이 제시되었다(Korzeniewski et al., 2013).

\section{Tankyrase inhibitor}

많은 연구를 통해 암 치료제로서의 tankyrase inhibitor의 중요성과 유용성이 보고되었다. 현재까지 JW74, XAV939, AZ1366, IWR-1, G007-LK, JW55, NVP-TNKS656, WIKI4, Tetrazoloquinoxaline 41 (Waaler et al., 2012; Lau et al., 2013; Stratford et al., 2014; Tian et al., 2014; Bao et al., 2012; Scarborough et al., 2017; Quackenbush et al., 2016; Arqués et al., 2016; Thomson et al., 2017) 등과 같은 tankyrase inhibitor 가 보고되었고, 암세포 치료에 효과를 보였다(Table 1). 대 표적인 XAV939, G007-LK, JW55는 $\beta$-catenin 안정성 표적 으로 tankyrase를 저해하여 AXIN을 안정화하고 $\beta$-catenin 분해를 촉진한다. 특히, $\mathrm{APC}$ 돌연변이 대장암 세포에서 WNT 신호 전달과 종양 성장을 억제하는 tankyrase inhibition의 확실한 효과가 입증됨에 따라 이를 바탕으로 한 tankyrase inhibitor가 발달하였다(Huang et al., 2009; Waaler 
et al., 2012; Lau et al., 2013). 구체적으로 XAV939와 G007$\mathrm{LK}$ 는 $\mathrm{APC}$ 돌연변이 대장암의 종양 성장을 억제한다는 것을 보여주었다(Wu et al., 2016). 또한, tankyrase inhibition 을 통한 WNT 신호 전달 경로의 길항 작용은 폐암 세포 에도 효과적인 것으로 보고되었고(Casás-Selves et al., 2012; Busch et al., 2013), 실제로 tankyrase inhibitor NVP-TNKS656 이 폐암 세포에 효과적임을 보여 준다(Wang et al., 2016). 최근 새로운 tankyrase inhibitor인 tetrazoloquinoxaline 41이 여러 종류의 암세포에서 세포주의 성장을 억제하는 효 과를 보여 잠재적인 타깃으로의 가능성이 보고되었다 (Thomson et al., 2017). Tankyrase inhibitor 단독으로의 암세 포 저해 효과 뿐만 아니라 다른 inhibitor들과의 병합에 인 한 항암 효과(Zhang et al., 2010; Ozaki et al., 2012; Lu et al., 2013)도 보고된 바 새로운 항암 치료 가능성 및 치료 전 략이 제시될 것으로 예상된다.

\section{결 론}

Tankyrase는 다양한 세포 기능에 관여되어 있으며 중요 한 암 치료 표적이다. Tankyrase 단백질은 AXIN, PTEN 및 $\mathrm{AMOT}$ 와 같은 종양 억제 인자를 조절하고 암의 발병 원 인인 telomere 유지 및 유사 분열 조절에 관여한다. Tankyrase inhibitor는 WNT, AKT 및 YAP를 비롯한 다양한 발암 경로를 표적으로 하기 때문에 tankyrase가 암 치료의 효과 적인 표적이 될 수 있다. 많은 연구를 통해 암 치료제로 서의 tankyrase inhibitor의 중요성과 유용성이 보고되었다. 특히, tankyrase inhibition는 APC 돌연변이 결장 직장 암세 포에서 WNT 신호 전달 경로와 종양 성장을 억제하는 확 실한 효과가 입증됨에 따라 이를 바탕으로 한 tankyrase inhibitor가 발달하였다. 예를 들어, XAV939와 G007-LK는 $\mathrm{APC}$ 돌연변이 대장암 세포의 종양 성장 억제 효과를 확 실히 보여주었다. 따라서 tankyrase inhibitor가 앞으로 APC 돌연변이 대장암에서 선택적인 항암 치료제 개발에 중요 하다고 사료된다. 또한, tankyrase inhibitor인 P-TNKS656이 폐암 세포에 효과적이고 새로운 tankyrase inhibitor인 tetrazoloquinoxaline 41 이 여러 종류의 암세포에서 세포주의 성 장을 억제하는 효과가 보고된 바 tankyrase inhibitor가 대 장암 외에도 다른 암에서도 효과가 있을 것으로 예상된다. Tankyrase 단백질의 새로운 타깃과 메커니즘에 관련된 결 과들이 보고되고 있는 바 이를 바탕으로 앞으로 다양한 암에 대한 더 발전되고 진화된 tankyrase inhibitor가 개발 되고 새로운 치료 전략이 제시될 것으로 예상된다.

\section{ACKNOWLEDGEMENTS}

This research was supported by the National Research Foundation of Korea (NRF-2015R1C1A1A02037631 to K.M.K.).

\section{CONFLICT OF INTEREST}

The author declares no conflict of interest.

\section{REFERENCES}

Arqués O, Chicote I, Puig I, Tenbaum SP, Argilés G, Dienstmann R, Fernández N, Caratù G, Matito J, Silberschmidt D, Rodon J, Landolfi S, Prat A, Espín E, Charco R, Nuciforo P, Vivancos A, Shao W, Tabernero J, Palmer HG. Tankyrase Inhibition Blocks Wnt/ $\beta$-Catenin Pathway and Reverts Resistance to PI3K and AKT Inhibitors in the Treatment of Colorectal Cancer. Clinical Cancer Research. 2016. 22: 644-656.

Bao R, Christova T, Song S, Angers S, Yan X, Attisano L. Inhibition of tankyrases induces Axin stabilization and blocks Wnt signaling in breast cancer cells. PloS One. 2012.7: e48670.

Beneke S, Bürkle A. Poly (ADP-ribosyl) ation in mammalian ageing. Nucleic Acids Research. 2007. 35: 7456-7465.

Blackburn EH, Gall JG. A tandemly repeated sequence at the termini of the extra chromosomal ribosomal RNA genes in Tetrahymena. Journal of Molecular Biology. 1978. 120: 33-53.

Boveri T. Concerning the origin of malignant tumours by Theodor Boveri. Translated and annotated by Henry Harris. Journal of Cell Science. 2008. 121: 1-84.

Bürkle A. Poly (ADP-ribose). The most elaborate metabolite of $\mathrm{NAD}^{+}$. FEBS Journal. 2005. 272: 4576-4589.

Busch AM, Johnson KC, Stan RV, Sanglikar A, Ahmed Y, Dmitrovsky E, Freemantle SJ. Evidence for tankyrases as antineoplastic targets in lung cancer. BMC Cancer. 2013. 13: 211.

Casás-Selves M, Kim J, Zhang Z, Helfrich BA, Gao D, Porter CC, Scarborough HA, Bunn PA Jr, Chan DC, Tan AC, DeGregori J. Tankyrase and the canonical Wnt pathway protect lung cancer cells from EGFR inhibition. Cancer Research. 2012. 72: 4154 -4164 .

C.G.A. Network. Comprehensive molecular characterization of human colon and rectal cancer. Nature. 2012. 487: 330-337.

Chang P, Coughlin M, Mitchison TJ. Tankyrase-1 polymerization of poly (ADP-ribose) is required for spindle structure and function. Nature Cell Biology. 2005. 7: 1133-1139.

Chang W, Dynek JN, Smith S. TRF1 is degraded by ubiquitinmediated proteolysis after release from telomeres. Genes \& 
Development. 2003. 17: 1328-1333.

Chang W, Dynek JN, Smith S. NuMA is a major acceptor of poly (ADPribosyl) ation by tankyrase 1 in mitosis. Biochemical Journal. 2005. 391: 177-184.

Clevers H. Wnt/ $\beta$-catenin signaling in development and disease. Cell. 2006. 127: 469-480.

Dong J, Feldmann G, Huang J, Wu S, Zhang N, Comerford SA, Gayyed MF, Anders RA, Maitra A, Pan D. Elucidation of a universal size-control mechanism in Drosophila and mammals. Cell. 2007. 130: 1120-1133.

Duensing S, Munger K. Centrosome abnormalities, genomic instability and carcinogenic progression. Biochimica et Biophysica Acta . 2001. 2: 81-88.

Ganem NJ, Godinho SA, Pellma D. A mechanism linking extra centrosomes to chromosomal instability. Nature. 2009. 460: 278-282.

Guerrero AA, Martinez AC, van Wely KH. Merotelic attachments and non-homologous end joining are the basis of chromosomal instability. Cell Division. 2010. 5: 13.

Guettler S, LaRose J, Petsalaki E, Gish G, Scotter A, Pawson T, Rottapel R, Sicheri F. Structural basis and sequence rules for substrate recognition by tankyrase explain the basis for cherubism disease. Cell. 2011. 147: 1340-1354.

Guo HL, Zhang C, Liu Q, Li Q, Lian G, Wu D, Li X, Zhang W, Shen Y, Ye Z, Lin SY, Lin SC. The Axin/TNKS complex interacts with KIF3A and is required for insulin-stimulated GLUT4 translocation. Cell Research. 2012. 22: 1246-1257.

Ha GH, Kim HS, Go H, Lee H, Seimiya H, Chung DH, Lee CW. Tankyrase-1 function at telomeres and during mitosis is regulated by Polo-like kinase-1-mediated phosphorylation. Cell death and Differentiation. 2012. 19: 321-332.

Haikarainen T, Krauss S, Lehtio L. Tankyrases: structure, function and therapeutic implications in cancer. Current Pharmaceutical Design. 2014. 20: 6472-6488.

Harvey KF, Zhang X, Thomas DM. The Hippo pathway and human cancer. Nature Reviews Cancer. 2013. 13: 246-257.

Huang SM, Mishina YM, Liu S, Cheung A, Stegmeier F, Michaud GA, Charlat O, Wiellette E, Zhang Y, Wiessner S, Hild M, Shi X, Wilson CJ, Mickanin C, Myer V, Fazal A, Tomlinson R, Serluca F, Shao W, Cheng H, Shultz M, Rau C, Schirle M, Schlegl J, Ghidelli S, Fawell S, Lu C, Curtis D, Kirschner MW, Lengauer C, Finan PM, Tallarico JA, Bouwmeester T, Porter JA, Bauer A, Cong F. Tankyrase inhibition stabilizes axin and antagonizes Wnt signalling. Nature. 2009. 461: 614-620.

Kim MK, Dudognon C, Smith S. Tankyrase 1 regulates centrosome function by controlling CPAP stability. EMBO Reports. 2012. 13: 724-732.

Kim MK, Smith S. Persistent telomere cohesion triggers a prolonged anaphase. Molecular Biology of the Cell. 2014. 25: 30 -40 .

Kim NW, Piatyszek MA, Prowse KR, Harley CB, West MD, Ho PL, Coviello GM, Wright WE, Weinrich SL, Shay JW. Specific association of human telomerase activity with immortal cells and cancer. Science. 1994. 266: 2011-2015.

Korzeniewski N, Hohenfellner M, Duensing S. The centrosome as potential target for cancer therapy and prevention. Expert Opinion on Therapeutic Targets. 2013. 17: 43-52.

Kraus W, Lis JT. PARP goes transcription. Cell. 2003. 113: 677 $-683$.

Lau T, Chan E, Callow M, Waaler J, Boggs J, Blake RA, Magnuson S, Sambrone A, Schutten M, Firestein R, Machon O, Korinek V, Choo E, Diaz D, Merchant M, Polakis P, Holsworth DD, Krauss S, Costa M. A novel tankyrase small-moleculeinhibitor suppresses APC mutation-driven colorectal tumor growth. Cancer Research. 2013. 73: 3132-3144.

Levaot N, Voytyuk O, Dimitriou I, Sircoulomb F, Chandrakumar A, Deckert M, Krzyzanowski PM, Scotter A, Gu S, Janmohamed S, Cong F, Simoncic PD, Ueki Y, La Rose J, Rottapel R. Loss of tankyrase-mediated destruction of $3 \mathrm{BP} 2$ is the underlying pathogenic mechanism of cherubism. Cell. 2011. 147: 1324 -1339 .

Li J, Yen C, Liaw D, Podsypanina K, Bose S, Wang SI, Puc J, Miliaresis C, Rodgers L, McCombie R, Bigner SH, Giovanella BC, Ittmann M, Tycko B, Hibshoosh H, Wigler MH, Parsons R. PTEN, a putative protein tyrosine phosphatase genemutated in human brain, breast, and prostate cancer. Science. 1997. 275: 1943-1947.

Li N, Zhang Y, Han X, Liang K, Wang J, Feng L, Wang W, Songyang Z, Lin C, Yang L, Yu Y, Chen J. Poly-ADP ribosylation of PTEN by tankyrases promotes PTEN degradation and tumor growth. Genes \& Development. 2015. 29: 157-170.

Liaw D, Marsh DJ, Li J, Dahia PL, Wang SI, Zheng Z, Bose S, Call KM, Tsou HC, Peacocke M, Eng C, Parsons R. Germline mutations of the PTEN gene in Cowden disease, an inherited breast and thyroid cancer syndrome. Nature Genetics. 1997. 16: 64-67.

Lin L, Sabnis AJ, Chan E, Olivas V, Cade L, Pazarentzos E, Asthana S, Neel D, Yan JJ, Lu X, Pham L, Wang MM, Karachaliou N, Cao MG, Manzano JL, Ramirez JL, Torres JM, Buttitta F, Rudin CM, Collisson EA, Algazi A, Robinson E, 
Osman I, Muñoz-Couselo E, Cortes J, Frederick DT, Cooper ZA, McMahon M, Marchetti A, Rosell R, Flaherty KT, Wargo JA, Bivona TG. The Hippo effector YAP promotes resistance to RAF and MEK-targeted cancer therapies. Nature Genetics. 2015. 47: 250-256.

Lu H, Lei Z, Lu Z, Lu Q, Lu C, Chen W, Wang C, Tang Q, Kong Q. Silencing tankyrase and telomerase promotes A549 human lung adenocarcinoma cell apoptosis and inhibits proliferation. Oncology Reports. 2013. 30: 1745-1752.

Luo X, Kraus WL. On PAR with PARP: cellular stress signaling through poly (ADP-ribose) and PARP-1. Genes \& Development. 2012. 26: 417-432.

Malanga M, Althaus FR. The role of poly (ADP-ribose) in the DNA damage signaling network. Biochemistry and Cell Biology. 2005. 83: 354-364.

Mo JS, Park HW, Guan KL. The Hippo signaling pathway in stem cell biology and cancer. EMBO Reports. 2014. 15: 642-656.

Nguyen DX, Chiang AC, Zhang XH, Kim JY, Kris MG, Ladanyi M, Gerald WL, Massagué J. WNT/TCF Signaling through LEF1 and HOXB9 Mediates Lung Adenocarcinoma Metastasis. Cell. 2009. 138: 51-62.

Ozaki Y, Matsui H, Asou H, Nagamach, A, Aki D, Honda H, Yasunaga S, Takihara Y, Yamamoto T, Izumi S, Ohsugi M, Inaba T. Poly-ADP ribosylation of Miki by tankyrase-1 promotes centrosome maturation. Molecular Cell. 2012. 47: 694 -706 .

Pacheco-Pinedo EC, Durham AC, Stewart KM, Goss AM, Lu MM, Demayo FJ, Morrisey EE. Wnt/ $\beta$-catenin signaling accelerates mouse lung tumorigenesis by imposing an embryonic distal progenitor phenotype on lung epithelium. Journal of Clinical Investigation. 2011. 121: 1935-1945.

Quackenbush KS, Bagby S, Tai WM, Messersmith WA, Schreiber A, Greene J, Kim J, Wang G, Purkey A, Pitts TM, Nguyen A, Gao D, Blatchford P, Capasso A, Schuller AG, Eckhardt SG, Arcaroli JJ. The novel tankyrase inhibitor (AZ1366) enhances irinotecan activity in tumors that exhibit elevated tankyrase and irinotecan resistance. Oncotarget. 2016. 7: 28273-28285.

Riffell JL, Lord CJ, Ashworth A. Tankyrase-targeted therapeutics: expanding opportunities in the PARP family. Nature Reviews Drug Discovery. 2012. 11: 923-936.

Rubinfeld B, Albert I, Porfiri E, Fiol C, Munemitsu S, Polakis P. Binding of GSK3beta to the APC-beta-catenin complex and regulation of complex assembly. Science. 1996. 272: 1023 -1026 .

Scarborough HA, Helfrich BA, Casás-Selves M, Schuller AG,
Grosskurth SE, Kim J, Tan AC, Chan DC, Zhang Z, Zaberezhnyy V, Bunn PA, DeGregori J. AZ1366: An Inhibitor of Tankyrase and the Canonical Wnt Pathway that Limits the Persistence of Non-Small Cell Lung Cancer Cells Following EGFR Inhibition. Clinical Cancer Research. 2017. 23: 1531 -1541 .

Shay JW, Bacchetti S. A survey of telomerase activity in human cancer. European Journal of Cancer. 1997. 33: 787-791.

Smith S, de Lange T. Tankyrase promotes telomere elongation in human cells. Current Biology. 2000. 10: 1299-1302.

Steck PA, Pershouse MA, Jasser SA, Yung WK, Lin H, Ligon AH, Langford LA, Baumgard ML, Hattier T, Davis T, Frye C, Hu R, Swedlund B, Teng DH, Tavtigian SV. Identification of a candidate tumour suppressor gene, MMAC1, at chromosome $10 \mathrm{q} 23.3$ that is mutated in multiple advanced cancers. Nature Genetics. 1997. 15: 356-362.

Stratford EW, Daffinrud J, Munthe E, Castro R, Waaler J, Krauss S, Myklebost O. The tankyrase-specific inhibitor JW74 affects cell cycle progression and induces apoptosis and differentiation in osteosarcoma cell lines. Cancer Medicine. 2014. 3: 36-46.

Thomson DW, Wagner AJ, Bantscheff M, Benson RE, Dittus L, Duempelfeld B, Drewes G, Krause J, Moore JT, Mueller K, Poeckel D, Rau C, Salzer E, Shewchuk L, Hopf C, Emery JG, Muelbaier M. Discovery of a Highly Selective Tankyrase Inhibitor Displaying Growth Inhibition Effects against a Diverse Range of Tumor Derived Cell Lines. Journal of Medicinal Chemistry. 2017. 60: 5455-5471.

Tian X, Hou W, Bai S, Fan J, Tong H, Xu H. XAV939 inhibits the stemness and migration of neuroblastoma cancer stem cells via repression of tankyrase 1. International Journal of Oncology. 2014. 45: 121-128.

Waaler J, Machon O, Tumova L, Dinh H, Korinek V, Wilson SR, Paulsen JE, Pedersen NM, Eide TJ, Machonova O, Gradl D, Voronkov A, von Kries JP, Krauss S. A novel tankyrase inhibitor decreases canonical Wnt signaling in colon carcinoma cells and reduces tumor growth in conditional APC mutant mice. Cancer Research. 2012. 72: 2822-2832.

Wang H, Lu B, Castillo J, Castillo J, Zhang Y, Yang Z, McAllister G, Lindeman A, Reece-Hoyes J, Tallarico J, Russ C, Hoffman G, Xu W, Schirle M, Cong F. Tankyrase Inhibitor Sensitizes Lung Cancer Cells to Endothelial Growth Factor Receptor (EGFR) Inhibition via Stabilizing Angiomotins and Inhibiting YAP Signaling. Journal of Biological Chemistry. 2016. 291: 15256-15266.

Wang W, Huang J, Chen J. Angiomotin-like proteins associate with 
and negatively regulate YAP. Journal of Biological Chemistry. 2011. 286: 4364-4370.

Wang W, Li N, Li X, Tran MK, Han X, Chen J. Tankyrase inhibitors Target YAP by Stabilizing Angiomotin Family Proteins. Cell Reports. 2015. 13: 524-532.

Wu X, Luo F, Li J, Zhong X, Liu K. Tankyrase 1 inhibitior XAV939 increases chemosensitivity in colon cancer cell lines via inhibition of the Wnt signaling pathway. International Journal of Oncology. 2016. 48: 1333-1340.

Yeh, TY, Sbodio JI, Tsun ZY, Luo B, Chi NW. Insulin-stimulated exocytosis of GLUT4 is enhanced by IRAP and its partner tankyrase. Biochemical Journal. 2007. 402: 279-290.

Zhang H, Yang MH, Zhao JJ, Chen L, Yu ST, Tang XD, Fang DC, Yang SM. Inhibition of tankyrase 1 in human gastric cancer cells enhances telomere shortening by telomerase inhibitors. Oncology Reports. 2010. 24: 1059-1065.

https://doi.org/10.15616/BSL.2018.24.3.150

Cite this article as: Kim MK. Tankyrase: Function and Tankyrase Inhibitor in Cancer. Biomedical Science Letters. 2018. 24: 150-156. 